\title{
O livro didático de ciências em questão: uma triangulação entre análises de unidades, concepção de professores da educação básica e visão de licenciandos em ciências biológicas
}

Julio Cesar Bresolin Marinho juliomarinho@unipampa.edu.br orcid.org/0000-0002-2313-500X Universidade Federal do Pampa (UNIPAMPA), São Gabriel, RS, Brasil

Ana Caroline Machado Gonçalves anamachado.363@gmail.com orcid.org/0000-0002-7121-8088 Universidade Federal do Pampa (UNIPAMPA), São Gabriel, RS, Brasil

Joseane Salau Ferraz joseaneferraz98@gmail.com orcid.org/0000-0001-6401-758x orcid.org/0000-0001-6401-758X (UNIPAMPA), São Gabriel, RS, Brasil

Gabriele Milbradt Glasenapp gabrielemglasenapp@gmail.com orcid.org/0000-0003-3278-7082 (UNIPAMPA), São Gabriel, RS, Brasil

Kevin Giovanni da Silva Garcia kevin.kgdsgarcia@gmail.com orcid.org/0000-0003-2576-9628 Universidade Federal do Pampa (UNIPAMPA), São Gabriel, RS, Brasil

Etienne Caroline Rodrigues Feliciani

ennefeliciani@gmail.com
orcid.org/0000-0003-1684-5094 (UNIPAMPA), São Gabriel, RS, Brasi

\section{RESUMO}

O objetivo do trabalho tratou-se em realizar uma triangulação de evidências entre as concepções de professores de Ciências da educação básica sobre o livro didático (LD), as análises de unidades de LD de Ciências utilizados em escolas do município de São Gabriel RS e por fim analisar a concepção de futuros professores de Ciências e Biologia que irão utilizar os LD em sua atuação profissional. A pesquisa, de abordagem qualitativa, configurou-se como exploratória. Como instrumento de pesquisa, foram utilizados dois questionários abertos para analisar as concepções dos participantes sobre o LD de Ciências, sendo um deles direcionado a professores de Ciência da educação básica e outro a acadêmicos de licenciatura em Ciências Biológicas. Os participantes da pesquisa consistiram em: seis acadêmicos do 5으 semestre do curso de licenciatura em Ciências Biológicas da Universidade Federal do Pampa - UNIPAMPA, Campus São Gabriel e três professoras de Ciências da rede pública do município de São Gabriel - RS. As professoras mencionaram que nunca receberam nenhum tipo de formação para a escolha do LD. Os discursos mostram que, exceto nas escolas particulares, o processo de escolha é feito pelos próprios professores. Evidenciamos que a escolha do livro é realizada a partir de critérios próprios. As professoras, geralmente, consideram os LD "bons". Em relação a quantidade de exemplares disponíveis para o número de alunos, por vezes, não é suficiente, inviabilizando que sejam levados para casa, sendo utilizados apenas na escola. O LD nas aulas de Ciências é empregado como um apoio, principalmente para a resolução de exercícios. Na análise das unidades do LD oito aspectos foram pontuados: apresentação; linguagem; recursos visuais; exercícios e atividades propostas; relação Ciência, Tecnologia e Sociedade; contextualização e interdisciplinaridade; material complementar; problemas e/ou faltas observadas. Nas percepções dos licenciandos sobre o LD observou-se que, anteriormente a atividade analítica, essas eram equivocadas. Os principais aspectos positivos evidenciados no LD, pelos licenciandos, foram as atividades propostas. Como falhas/problemas encontrados no material, a maioria apontou os textos, alegando que eram muito resumidos. Os licenciandos apontaram que a atividade de análise dos LD colaborou para a sua formação, contribuindo com o desenvolvimento de um maior senso crítico; proporcionando reflexão sobre como temas da Ciência são propostos para serem desenvolvidos na educação básica; possibilitou terem outra opinião sobre o uso LD, visualizando que pode ser um recurso potente. Por meio da triangulação de dados inferimos que é necessário um trabalho articulado, no qual os cursos de licenciatura problematizem aspectos relacionados a escolha do LD e, apresentem as potencialidades de sua utilização para os futuros professores; realização de análises periódicas das coleções aprovadas pelo PNLD, para verificar como os temas estão sendo propostos, bem como a qualidade dos exemplares; trabalhos de formação continuada com professores, para que consigam estabelecer critérios claros, os quais possibilitem a realização de uma escolha mais consciente e crítica do LD que irão utilizar.

PALAVRAS-CHAVE: Livro didático. Ensino de Ciências. Formação de professores. 


\section{INTRODUÇÃO}

O livro didático (LD), ainda hoje, "na maioria das salas de aula, continua prevalecendo como principal instrumento de trabalho do professor, embasando significativamente a prática docente" (DELIZOICOV; ANGOTTI; PERNAMBUCO, 2011, p. 36). O LD é um objeto familiar de professores e alunos, assumindo um papel fundamental no desenvolvimento do conhecimento, bem como na condução das práticas pedagógicas (RUDEK; KIEREPKA; GÜLLICH, 2015), além disso atua como "determinante dos modos como o ensino e o currículo são organizados" (GÜLLICH; PANSERA-DE-ARAÚJO; EMMEL, 2010, p. 1910). No Ensino de Biologia, o LD possui um duplo papel, sendo utilizado "tanto na determinação do conteúdo dos cursos como na determinação da metodologia usada em sala de aula, sempre no sentido de valorizar um ensino informativo e teórico" (KRASILCHIK, 2008, p. 65). Com esse destaque fornecido a esse recurso didático - LD - se faz pertinente diversificadas análises.

A literatura atual tem apresentado, de forma significativa, diversos estudos que possuem os LD como corpus de investigação. O segundo tópico desse trabalho apresentará alguns trabalhos que foram desenvolvidos e publicados, de 2003 a 2018, em revistas especializadas da área de Educação em Ciências sobre tal temática. De forma geral, podemos observar que os trabalhos sobre LD desenvolvidos, em sua maioria, se restringem a análise de determinado conteúdo em um ou mais exemplares. No entanto, esse trabalho se diferencia dos demais por realizar uma triangulação de evidências, visto que procuramos conhecer as concepções de professores de Ciência da educação básica sobre o LD, bem como realizar análises sobre algumas unidades de LD utilizados em escolas do município de São Gabriel (RS) e por fim analisar a concepção de futuros professores de Ciências e Biologia que irão utilizar os LD em sua atuação profissional.

\section{OS LIVROS DIDÁTICOS NAS INVESTIGAÇÕES EM ENSINO DE CIÊNCIAS}

Como já mencionamos, são inúmeras as publicações que têm os LD como objeto de investigação. Dessa forma, optamos por revisitar os trabalhos publicados nas revistas nacionais mais prestigiadas da área de Educação em Ciências. Optamos pelas duas revistas qualificadas como A1 (Área de Ensino) na última avaliação (2013-2016) da Coordenação de Aperfeiçoamento de Pessoal de Nível Superior (CAPES), sendo elas: Ciência e Educação e Ensaio: Pesquisa em Educação em Ciências. As duas revistas encontram-se indexadas em uma das bases bibliográficas latino americanas mais acessadas e prestigiadas, a Scientific Eletronic Library Online - SciELO (www.scielo.br), que reúne periódicos online e permite acesso livre e gratuito ao texto completo dos artigos. A busca foi realizada durante o mês de agosto de 2018, na página das revistas na SciELO ${ }^{1}$. Para realizar a pesquisa foi inserido o termo "livro didatico" no campo "pesquisa" presente na página inicial de cada um dos periódicos. Optamos por não utilizar nenhum filtro, deixando a busca em "todos os índices". Também não restringimos um período específico da publicação dos artigos.

A busca resultou em um número de 30 artigos presentes na revista Ciência e Educação e 11 da revista Ensaio: Pesquisa em Educação em Ciências, o que totalizou 41 artigos que foram analisados, em um primeiro momento, em relação 
ao título, resumo e palavras-chave. Após essa primeira análise foram excluídos 11 trabalhos (9 da revista Ciência e Educação e 2 da revista Ensaio: Pesquisa em Educação em Ciências), visto que não se relacionavam com nossa temática de interesse. Os 30 artigos que restaram, foram organizados em temáticas, conforme o enfoque de cada um. Os enfoques podem ser observados na Tabela 1.

Tabela 1 - Número de artigo e percentual conforme o enfoque dos artigos

\begin{tabular}{c|c|c}
\hline Enfoque dos artigos & No de artigos & Percentual \\
\hline $\begin{array}{c}\text { Análise de LD de Biologia } \\
\text { Análise da abordagem da História e Filosofia da } \\
\text { Ciência nos LD }\end{array}$ & 10 & $33,33 \%$ \\
\hline Análise de LD de Física & 3 & $13,33 \%$ \\
\hline Análise de conteúdos de Ciências LD dos anos \\
iniciais & 2 & $10,00 \%$ \\
\hline Gênero e sexualidade nos LD & 2 & $6,66 \%$ \\
\hline Análise de LD de Química & 2 & $6,66 \%$ \\
\hline Análise do Guia dos LD de Ciências & 1 & $6,66 \%$ \\
\hline Analisa a temática do LD para o ensino de \\
Ciências no Brasil & 1 & $3,33 \%$ \\
\hline Educação alimentar e nutricional no LD & 1 & $3,33 \%$ \\
\hline Formação de conceitos científicos & 1 & $3,33 \%$ \\
\hline Concepção de Ciência nos LD & 1 & $3,33 \%$ \\
\hline Pesquisas sobre LD & 1 & $3,33 \%$ \\
\hline Total & 30 & $3,33 \%$ \\
\hline
\end{tabular}

Fonte: Autoria própria (2019).

Pelos enfoques apresentados na Tabela 1 podemos ver a predominância de artigos que se ocupam na investigação dos LD de Biologia (33,33\%). Dentre os conteúdos de Biologia investigados tem-se: a genética humana (XAVIER; FREIRE; MORAES, 2006; PROCHAZKA; FRANZOLIN, 2018); a biologia animal (SOUZA; ROCHA, 2017); os morcegos (BARREIRO; ORTENCIO FILHO, 2016); a dengue (ASSIS; PIMENTA; SCHALL, 2013); a biodiversidade (CARDOSO-SILVA; OLIVEIRA, 2013); as leishmanioses (FRANCA; MARGONARI; SCHALL, 2011); a sistemática e a filogenética (RODRIGUES; JUSTINA; MEGLHIORATTI, 2011); o ciclo do nitrogênio (COUTINHO; SOARES, 2010); a virologia (BATISTA; CUNHA; CANDIDO, 2010).

A abordagem da História e Filosofia da Ciência (HFC) nos LD esteve presente em quatro artigos. Dois analisaram aspectos da HFC nos $L D$ relacionada a temáticas biológicas (CARNEIRO; GASTAL, 2005; SILVA, PASSOS; BOAS, 2013) e outros dois trabalhos buscaram analisar a História da Ciência nos LD de Química (SILVA; MARTINS, 2009; VIDAL; PORTO, 2012).

O enfoque "os professores e o LD" aglutinou três artigos. Rosa e Mohr (2016) investigaram aspectos relacionados à seleção e ao uso do LD de Ciências por professores de Florianópolis. O artigo de Carneiro, Santos e Mól (2005) discutiu a 
Cassab e Martins (2008) buscou os sentidos que professores de Ciências atribuem ao LD durante a escolha do material.

Em relação a análise dos LD de Química e Física encontramos três trabalhos, um relacionado a Química (BERNARDINO; RODRIGUES; BELLIN, 2013) e dois a Física (RIBEIRO; MARTINS, 2007; LEITE; GARCIA, 2018). O trabalho de Bernardino, Rodrigues e Bellin (2013) procurou identificar e analisar as analogias presentes no LD de Química de escolas do Paraná. Já os artigos que analisavam aspectos da Física tiveram enfoques bem diferentes. Ribeiro e Martins (2007) discutiram o potencial das narrativas no ensino de Ciências, por meio da análise da história de Arquimedes e a coroa do Rei Hierão, publicadas em LD de Física. Já o estudo de Leite e Garcia (2018) analisou aspectos da formação inicial de licenciandos em Física relacionados à sua preparação para o uso do LD do Ensino Médio.

A "análise de conteúdos de Ciências LD dos anos iniciais" e "gênero e sexualidade nos LD" foram dois outros enfoques evidenciados, cada um deles teve dois trabalhos publicados nos periódicos. Os estudos sobre conteúdos de Ciências nos LD dos anos iniciais residiram em: obter informações sobre a Química apresentada nas séries iniciais por meio da análise de 12 coleções de Ciências (1a a 4a série) aprovadas no Programa Nacional do Livro Didático - PNLD/2007 (MORI; CURVELO, 2014); e analisar em LD dos anos iniciais as possíveis causas das lacunas explicativas que alunos dos anos finais apresentam sobre o sistema respiratório (RUPPENTHAL; SCHETINGER, 2013). Já as investigações sobre gênero e sexualidade residiram em: analisar a abordagem da educação sexual nos LD distribuídos pelo PNLD/ 2014 (LADISLAU FILHA; RIBEIRO, 2016); e realizar uma leitura sobre as identidades de gênero nos LD de Ciências, da 1a e 2a série do Ensino Fundamental (MARTINS; HOFFMANN, 2007).

Por fim, apresentamos seis trabalhos que não puderam ser aglutinados junto a outros enfoques devido suas especificidades, abordando: a análise da temática do LD para o Ensino de Ciências no Brasil e apresentação de alternativas a este recurso (MEGID NETO; FRACALANZA, 2003); o levantamento das pesquisas realizadas envolvendo LD e educação ambiental (MARPICA; LOGAREZZI, 2010); o processo de formação e desenvolvimento de conceitos científicos em LD (LIMA; AGUIAR JUNIOR; DE CARO, 2011); as interfaces que o LD exerce na produção conceitual de práticas pedagógicas, de ideologias e na produção de sentido nas ciências e em seu ensino (GULLICH; SILVA, 2013); a análise do Guia dos LD de Ciências, com o intuito de observar a mudança discursiva que vem ocorrendo no campo da Educação em Ciências, na qual a educação para a cidadania assume uma posição de destaque (VILANOVA, 2015); a educação alimentar e nutricional no LD (GREENWOOD; FONSECA, 2016).

Assim, podemos verificar que o LD de Biologia possui destaque nas investigações dos pesquisadores da área de Ensino de Ciências, correspondendo a $33,33 \%$ do enfoque dos trabalhos identificados na SciELO. No entanto, nosso estudo vai além de simplesmente analisar os conteúdos. Diferencia-se por buscar uma triangulação da análise articulada as concepções, sobre o LD, de professores de Ciência em exercício, bem como analisar a concepção de futuros professores de Ciências e Biologia, os quais irão utilizar os LD em sua atuação profissional. 


\section{METODOLOGIA}

A pesquisa, de abordagem qualitativa, configurou-se como exploratória (SEVERINO, 2007), visto que buscamos conhecer as concepções de professores de Ciência em exercício sobre o LD, realizar análises sobre algumas unidades de LD de Ciências utilizados em escolas do município de São Gabriel - RS e analisar a concepção de futuros professores de Ciências e Biologia (licenciandos).

Como instrumento de pesquisa, optamos pela utilização de questionários abertos (Anexo 1) para analisar as concepções dos participantes sobre o LD de Ciências. Elaboramos um questionário que foi respondido por professores de Ciência em atuação e outro direcionado aos acadêmicos do 5o semestre de um curso de licenciatura em Ciências Biológicas. Optamos por utilizar questionários do tipo aberto, por compreender que eles possibilitam a elaboração de respostas dos sujeitos por meio das suas próprias palavras, a partir de sua elaboração pessoal (SEVERINO, 2007; MOREIRA, 2016). Como Moreira (2016), acreditamos que perguntas abertas favorecem a exploração mais a fundo do tema.

O questionário aplicado aos professores de Ciência em exercício era dividido em duas partes: (i) cinco questionamentos referente aos dados pessoais dos participantes (idade, gênero, formação inicial, formação em nível de pósgraduação, atuação profissional); (ii) seis questões abertas referentes a utilização do LD. As questões foram organizadas com base no trabalho de Rosa e Mohr (2016), os quais elegeram quatro blocos para entrevistarem professores de Ciências sobre o LD, sendo eles: (I) formação do professor para a escolha do livro, (II) processo de escolha do material, (III) aspectos relativos a quantidade e qualidade e (IV) uso do livro pelos sujeitos de pesquisa. O questionário desenvolvido com os acadêmicos da licenciatura em Ciências Biológicas era composto por duas partes: (i) três questionamentos referentes aos dados pessoais dos participantes (idade, gênero, semestre que estavam cursando); (ii) quatro questões abertas referentes a suas compreensões sobre o LD.

Para a análise das unidades, os alunos do curso de Licenciatura em Ciências Biológicas foram orientados a ir à escola em que realizariam seu Estágio Supervisionado no Ensino Fundamental e verificar com o(a) professor(a) da turma, na qual o estágio seria realizado, qual o LD era utilizado. Nesse contato com o(a) professor(a) os alunos conseguiram o material para ser analisado - em algumas escolas os professores disponibilizaram os LD e, em outras ele foi disponibilizado para os alunos tirarem cópia. Após obterem os LD, escolheram uma unidade (a qual seria trabalhada durante o estágio no próximo semestre), para realização da análise, a qual foi feita de acordo com uma ficha (Anexo 2) elaborada baseada em critérios estabelecidos por Mohr (2000) e El-Hani, Roque e Rocha (2011).

\section{PARTICIPANTES DO ESTUDO}

Os participantes da pesquisa eram: seis (6) acadêmicos do 50 semestre do curso de Ciências Biológicas - Licenciatura da Universidade Federal do Pampa UNIPAMPA, Campus São Gabriel - RS e três (3) professoras de Ciências da rede pública do município de São Gabriel - RS. As três professoras possuíam uma carga horária de 40 horas semanais e atuavam no Ensino Fundamental e Médio. No quadro 1 , podemos observar o perfil das professoras participantes do estudo. 


\begin{tabular}{|c|c|c|c|}
\multicolumn{4}{|c}{ Quadro 1-Perfil das professoras participantes do estudo } \\
\hline Dados & Professora A & Professora B & Professora C \\
\hline Idade & 25 anos & 30 anos & 52 anos \\
\hline Formação inicial & $\begin{array}{c}\text { Licenciatura em } \\
\text { Ciências Biológicas } \\
(2016)\end{array}$ & $\begin{array}{c}\text { Licenciatura em } \\
\text { Ciências Biológicas } \\
(2010)\end{array}$ & $\begin{array}{c}\text { Licenciatura em } \\
\text { Ciências/Habilitação } \\
\text { Matemática (2016) }\end{array}$ \\
\hline Pós-Graduação & $\begin{array}{c}\text { Especialização em } \\
\text { Metodologia do } \\
\text { ensino de Ciências } \\
\text { Biológicas (2018) }\end{array}$ & $\begin{array}{c}\text { Mestrado em } \\
\text { Ciências Biológicas } \\
(2017)\end{array}$ & $\begin{array}{c}\text { Especialização em } \\
\text { Sistemas Ecológicos } \\
\text { e Educação } \\
\text { Ambiental (2007) }\end{array}$ \\
\hline Início da docência & 2017 & 2017 & 1995 \\
\hline
\end{tabular}

Fonte: Autoria própria (2019).

\title{
CONCEPÇÕES DAS PROFESSORAS DA EDUCAÇÃO BÁSICA SOBRE O LD
}

As três professoras que participaram do estudo mencionaram que nunca receberam nenhum tipo de formação para a escolha do LD. Em relação a escolha, mencionaram o seguinte:

\begin{abstract}
Nas escolas estaduais do Estado do RS, várias editoras mandam livros de acordo com as normas atuais exigidas pelo MEC [Ministério da Educação] (atualmente os livros serão regidos pelas normas da BNCC [Base Nacional Comum Curricular]) e os professores escolhem os que mais lhe agradam dentro da sua disciplina. Nas escolas particulares, quem escolhe os livros ou até mesmo o sistema trabalhado, é a equipe diretiva, os professores não têm participação nessa parte (Professora A).
\end{abstract}

[...] é realizada da seguinte maneira: a editora envia vários livros didáticos e o professor faz a escolha, esse livro será utilizado por 3 anos (Professora B).

Os professores reúnem-se e fazem uma análise criteriosa dos livros didáticos, escolhendo três opções. Após a escolha passam para a supervisão. A supervisão passa para o sistema (MEC) (Professora C).

Evidenciamos, assim como Zambon e Terrazzan (2013) e Basso e Terrazzan (2015a; 2015b) que o processo de escolha dos LD é "disparado" mediante o momento em que as editoras enviam cópias dos exemplares para as escolas. Os discursos mostram também que, exceto nas escolas particulares, o processo de escolha é feito pelos próprios professores que se reúnem e realizam uma análise na qual selecionam os que mais Ihe agradam. Tal resposta converge com o estudo de Rosa e Mohr (2016), no qual os professores de Ciências entrevistados mencionaram que a seleção do LD é de sua responsabilidade e declararam não sofrer nenhum constrangimento com indicações ou orientações externas.

Zambon e Terrazzan (2013) evidenciaram que para o processo de escolha dos LD acabam sendo realizados encontros na sala de professores, durante o intervalo, parecendo "ser, inclusive, nesses encontros breves que a maioria dos professores troca informações e toma decisões acerca dos livros didáticos" (p. 594). Tal evidência vai em oposição ao que foi relatado pela professora C, a qual mencionou ser realizada uma análise criteriosa pelos professores em conjunto. No entanto, Basso e Terrazzan (2015b), evidenciaram que as escolas analisadas organizam, no mínimo, um encontro para a escolha dos LD e constataram que, de uma maneira 
geral, os professores participaram do processo de escolha do LD e que essa participação se dá

de forma coletiva, geralmente em reuniões pedagógicas destinadas a esse fim, reunindo todos ou uma parcela considerável de professores; nesses eventos, os professores puderam analisar os livros e manifestar suas ideias e opiniões sobre os materiais. Esse momento de coletividade é, muitas vezes, considerado pelo professor como aspecto positivo do processo de escolha, pois Ihe é dada a oportunidade de escolher, em conjunto com seus colegas de profissão, o material que melhor se adéqua ao seu trabalho (p. 265).

Pelo discurso das professoras participantes do nosso estudo, inferimos que a escolha do LD é realizada a partir de critérios próprios, indo de encontro ao postulado por Basso e Terrazzan (2015b). Tais autores visualizaram que os professores estabelecem vários critérios, mas acabam escolhendo os LD "conforme as imagens que possuem sobre seus alunos, considerando a linguagem utilizada no livro, os tipos de textos apresentados, os recursos gráficos, etc. Os critérios e a avaliação do PNLD não são levados em consideração" (p. 270). Emmel, Pansera-de-Araújo e Gullich (2014, p. 6689) evidenciaram que "muitos professores não escolhem adequadamente o livro didático, nem (re)conhecem os critérios do PNLD, o que resulta numa ação ingênua e desinformada".

Assim como Núñez e colaboradores (2003), entendemos que a seleção dos LD para o Ensino de Ciências "constitui uma responsabilidade de natureza social e política" (p. 2), bem como "constitui uma tarefa de importância vital para uma boa aprendizagem dos alunos" (p. 3).

Ao avaliar a qualidade do LD de Ciências, a professora A menciona que, tanto os [LD] das escolas públicas, quanto da rede privada "são muito bons". Já a professora B gostaria que no material tivesse "mais exercícios e sugestões de atividade extra", dentre essas "atividades extras" ela destacou sites e experimentos. Podemos ver que o relato das professoras A e B se somam aos dos professores que participaram do estudo de Basso e Terrazzan (2015b, p. 269), visto que a maioria desses professores avalia, a qualidade dos LD, "entre boa e regular, sendo que, em alguns aspectos, os LD precisam ser aperfeiçoados de modo a atender às necessidades reais dos professores e das escolas".

Em relação a quantidade de exemplares de LD de Ciências disponíveis para o número de alunos da escola, a professora $\mathrm{A}$ nos diz que:

Sim, existe livro suficiente. Eles só levam para casa se a escola (no caso, a pública) permitir, e geralmente não permite, pois os livros têm validade de 3 anos. Nas escolas particulares os livros são comprados pelos alunos, então obviamente podem levar o material para onde quiserem.

Já as professoras $\mathrm{B}$ e $\mathrm{C}$ expressam que não há disponibilidade de livros para todos os alunos. A professora $B$ menciona que isso ocorre porque a escola possuí duas turmas de cada ano. A professora $\mathrm{C}$ salienta que os livros ficam na escola, pois "as vezes não vem a quantidade adequada". Alguns participantes do estudo de Rosa e Mohr (2016) também mencionaram que faltam LD em suas escolas, e argumentaram que isso ocorre pelo fato do número de alunos matriculados no ano de uso do livro ser superior àquele do ano em que ocorre a escolha. Basso e Terrazzan (2015b, p. 267) mostram que, "segundo o MEC, a quantidade de LD distribuída às escolas é baseada no censo escolar e as secretarias de educação recebem uma reserva técnica para atender as escolas que não receberam os livros 
em quantidade suficiente". No entanto, evidenciaram que "essa medida não tem suprido as necessidades escolares, pois sem a garantia de livros para todos os alunos, o trabalho do professor e o estudo do aluno podem ser prejudicados, uma vez que limita o estudo apenas no espaço escolar" (BASSO; TERRAZZAN, 2015b, p. 267).

A professora C aponta outra problemática, a qual se refere ao fato de os alunos levarem os livros para a casa e não trazerem para a realização das atividades em sala de aula. Nesse cenário, Basso e Terrazzan (2015b, p. 267) concebem que: "O não recebimento de livros em quantidade suficiente impede o aluno de levar o material para casa e, consequentemente de utilizar o livro como suporte para seus estudos, restringindo seu uso apenas às atividades em sala de aula".

Ao que tange a forma como as professoras utilizam os LD nas aulas de Ciências, fica claro, na resposta de duas delas, que utilizam o LD como apoio, principalmente para a resolução de exercícios: "Costumo utilizar o livro para me seguir nos conteúdos a serem trabalhos e também para tirar alguns exercícios trabalhados tanto em casa, quanto em sala de aula" (Professora A); "Apoio para os alunos acompanharem as explicações do professor. Para resolverem as atividades propostas em sala de aula e também para pesquisa" (Professora C).

Megid Neto e Fracalanza (2003) agruparam o uso que os professores alegam fazer do LD, em suas atividades docentes, em três grandes grupos. A utilização do LD descrita pelas professoras A e C convergem com o segundo grupo, no qual ele é

utilizado como apoio às atividades de ensino-aprendizagem, seja no magistério em sala de aula, seja em atividades extra-escolares, visando especialmente a leitura de textos, a realização de exercícios e de outras atividades ou, ainda, como fonte de imagens para os estudos escolares, aproveitando fotos, desenhos, mapas e gráficos existentes nos livros (MEGID NETO; FRACALANZA, 2003, p. 148).

A utilização do LD para trabalhar exercícios também foi evidenciada na investigação de Zambon e Terrazzan (2017). Os autores, procurando entender como os professores de Física se instrumentalizam a partir do LD no processo de organização das aulas, encontraram maior menção à utilização dos livros como fonte para organização de listagens de exercícios. No entanto, a professora B, apresenta uma visão diferente, ela alega que a escola exige o uso do LD, mas que ela não gosta, pois "apresenta muito conteúdo 'sem utilidade' e falta conteúdos básicos". Esse fragmento do discurso da professora é muito interessante, visto que vão ao encontro do que Megid Neto e Fracalanza (2003) já evidenciaram há algum tempo. Os autores concebem que os professores da educação básica têm se recusado, cada vez mais, a adotar de forma fiel os LD, fazendo constantes "adaptações das coleções, tentando moldá-las à sua realidade escolar e às suas conviç̧ões pedagógicas" (MEGID NETO; FRACALANZA, 2003, p.147). Dessa forma, segundo os autores, acabam reconstruindo o LD adotado. 


\section{ANÁLISE DAS UNIDADES DO LD}

O Projeto Araribá - Ciências é composto por quatro volumes (6으 ao 9ㅇaㅇ) divididos em unidades. As unidades abordam temáticas e/ou conceitos mais amplos, os quais são desenvolvidos em tópicos que organizam assuntos e conteúdos mais específicos. Nas unidades, encontram-se as seguintes seções: Glossário; Vamos Fazer; Tecnologia, Saúde ou Ambiente em Pauta; Coletivo ciências; Entrando na rede; Saiba mais!; Pensar ciência; Explore e Atividades ${ }^{3}$.

Analisamos 6 (seis) unidades de 3 (três) volumes diferentes do Projeto Araribá - Ciências, todos eles publicados em 2014 (Tabela 2). A escolha das unidades se deu a partir dos temas que os acadêmicos do curso de Ciências Biológicas Licenciatura da UNIPAMPA iriam trabalhar no seu estágio supervisionado.

Tabela 2 - Informações referentes as unidades do LD analisadas

\begin{tabular}{c|c|c|c}
\hline $\begin{array}{c}\text { Título da Unidade } \\
\text { A Água }\end{array}$ & $\begin{array}{c}\text { No de páginas } \\
\text { do livro }\end{array}$ & $\begin{array}{c}\text { No de páginas } \\
\text { da unidade }\end{array}$ & $\begin{array}{c}\text { Ano } \\
\text { destinado }\end{array}$ \\
\hline Animais Vertebrados & 232 & 14 & 6o ano \\
\hline Reino das Plantas I & 248 & 24 & 7 o ano \\
\hline Evolução Biológica & 248 & 13 & 7o ano \\
\hline Genética & 224 & 27 & 7o ano \\
\hline Adolescência e reprodução humana & 224 & 24 & 8o ano \\
\hline
\end{tabular}

Fonte: Autoria própria (2019).

A análise se ocupou de oito aspectos: apresentação das unidades; linguagem; recursos visuais; exercícios e atividades propostas; relação Ciência, Tecnologia e Sociedade-CTS; contextualização e interdisciplinaridade; material complementar; problemas e/ou faltas observadas nas unidades.

\section{APRESENTAÇÃO DAS UNIDADES}

$\mathrm{Na}$ abertura de todas as unidades são apresentadas imagens e problematizações a respeito do conteúdo abordado. Na abertura da unidade que aborda o reino das plantas são apresentados dois quadros, um nomeado de "Por que estudar esta unidade" e o outro "Começando a unidade". Esses têm o intuito de instigar o aluno a se interessar pelo tema que vai ser abordado, por meio de perguntas: "Como as plantas obtém o seu alimento?"; "As plantas respiram, quando?"; "Como as plantas se reproduzem?". Acreditamos que essas questões têm uma função importante, pois servem para avaliar o conhecimento prévio da turma, auxiliando o professor na escolha pela forma mais adequada para trabalhar tal conteúdo. O mesmo ocorre na unidade que aborda a adolescência e a reprodução humana, na qual questiona-se a importância de estudar o tema e também apresenta a importância de conhecermos as mudanças que ocorrem durante a vida em nosso corpo. Para mobilizar os alunos algumas perguntas são lançadas para serem respondidas posteriormente, ao longo da unidade, como por exemplo: "Você sabe como evitar uma gravidez?"; "Conhece métodos de prevenção de DSTs?". 
Evidenciamos que essa forma de realizar a apresentação dos temas, no início das unidades, acaba por expor um problema aos alunos, permitindo que fiquem instigados em aprender sobre o conteúdo que será tratado, bem como ancora os conhecimentos anteriores com os novos. Dessa forma, encontra-se de acordo com o primeiro momento da metodologia do ensino na aula (orientação inicial dos objetivos de ensino e aprendizagem) proposto por Libâneo (1994).

\section{LINGUAGEM}

Concebemos que a linguagem científica é bastante particular, o que implica uma dificuldade em sua compreensão pelos sujeitos. No ambiente escolar, o Ensino de Ciências também enfrenta esse obstáculo tendo em vista que, muitas vezes, é ali que o aluno acaba tendo o primeiro contato com termos técnicocientíficos. Braga e Mortimer (2011) destacam que a linguagem científica possui suas especificidades, e ao reconhecê-las, fica claro que para compreender a ciência é necessário aprender a linguagem utilizada por ela.

Nas unidades analisadas, de maneira geral, os textos apresentam uma linguagem formal de fácil compreensão. Quanto ao vocabulário utilizado nas unidades, este é bastante claro, com palavras que os alunos conhecem e encontram-se presentes em seu cotidiano. As palavras que não são familiares, como: genes, genoma e cariótipo, estavam claramente explicadas no próprio texto. No entanto, é encontrado em algumas páginas, um pequeno glossário com palavras que podem ser desconhecidas pelos alunos, como por exemplo: esperma, orgasmo, cloaca, planctônicos, ovíparos, naturalista, galgado, neocolonialismo, biomassa e ergonomia. Em outros momentos, os glossários estavam associados com imagens para auxiliar ainda mais o entendimento dos alunos. Um exemplo que podemos mencionar refere-se ao termo "estróbilo". Esse conceito foi apresentado na unidade que tratava do reino das plantas, quando abordava o ciclo reprodutivo das gimnospermas, junto ao glossário encontrava-se uma imagem da estrutura.

A presença de um glossário no LD é fundamental para melhor definição dos termos técnico-científicos, pois possibilita que o estudante busque seu significado no material disponível. A presença de definições ao longo do texto é também uma ferramenta enriquecedora da formação de pensamento científico, pois dessa forma é possível acessar, em primeira mão, o significado da palavra, havendo a possibilidade de que este a associe a outros termos já conhecidos do seu cotidiano. Entretanto, nesta ferramenta conceituam-se termos, o que apenas dá significado à palavra, limitando a capacidade do aluno em relacionar os termos aprendidos ao seu cotidiano (LIMA, AGUIAR JUNIOR; DE CARO, 2011). Para Jotta (2008), outro instrumento para o entendimento dos termos científicos é o esclarecimento da etimologia da palavra, ou seja, como se deu sua formação e origem.

\section{RECURSOS VISUAIS}

Consideramos como recursos visuais as imagens, os desenhos, os esquemas e as fotos apresentadas. Nas unidades analisadas todos são contextualizados, apropriados, diretos e possuem relação com a abordagem dos conteúdos ao longo 
do texto. As representações são coloridas e visualmente atrativas, proporcionando aos alunos uma forma mais sólida de compreender os mecanismos e conceitos abordados. Junto aos diversos recursos visuais encontra-se uma breve explicação sobre o que está sendo exposto, bem como as respectivas fontes.

Acreditamos que o uso de imagens auxilia os alunos na compreensão do conteúdo, já que podem ter uma percepção visual associada àquilo que estão lendo. No Ensino de Ciências as imagens se tornam aliadas importantes do professor, visto que a área abrange uma gama de conceitos, leis e teorias que se tornam difíceis de serem explicadas sem a utilização desse recurso (LAIA, 2016).

No material analisado, podemos destacar a riqueza de recursos visuais utilizados na unidade sobre os vertebrados. Esses mostravam as diferenças entre os grupos animais, as quais, muitas vezes, são difíceis de serem analisadas pelos alunos. Nas bordas das páginas eram apresentadas imagens de diversos animais contendo na legenda o nome da espécie, o local em que podem ser encontrados e alguma curiosidade sobre $o$ animal. Outros recursos visuais mostram problemáticas para a saúde pública e ambiental no Brasil. Na unidade sobre a água é apresentada uma imagem que ilustra um córrego onde existe o despejo de esgoto irregular e também contendo um volume muito grande de lixo. Na própria descrição da foto é mencionado que nesse mesmo ambiente convivem pessoas, animais e plantas, as quais correm o risco de serem contaminadas por alguma doença. Assim, compreendemos que as imagens vão além do papel ilustrativo, pois possibilitam aos alunos relaciona-las as situações cotidianas, bem como explorar o mundo micro e macroscópico.

\section{EXERCÍCIOS E ATIVIDADES PROPOSTAS}

As atividades são de níveis variados - desde questões de baixa complexidade que pedem apenas para o discente trocar palavras ou substituir termos, até questões mais complexas que exigem tomada de decisões perante determinadas situações-problema. Nesse último caso, demandavam que os alunos se posicionassem, relatando: "O que você faria?"; "Você concordaria?". Segundo Pedrosa (2001) essas atividades, que estimulam a participação do discente, contribuem para o desenvolvimento da comunicação e da argumentação. Assim, evidenciamos que esses exercícios colaboram para o aperfeiçoamento da capacidade cognitiva do indivíduo.

Algumas atividades propostas ao longo da unidade apresentavam questões que exigiam que os alunos desenvolvessem um olhar científico. Evidenciamos que essas foram bem elaboradas, pois instigam que os alunos pensem antes de responder e que utilizem outras fontes de consulta além do LD. Tal tipo de atividade vai além daquela resposta que consiste em uma cópia fiel do que está em alguma parte do livro. Uma dessas questões é intitulada "Pensar Ciência", a qual expõe um texto sobre as paixões de Darwin, contando brevemente a biografia do naturalista. Após o texto questiona-se: "Como os interesses pessoais de Darwin influenciaram nas suas pesquisas e descobertas?". Posteriormente, os autores sugerem a discussão com os colegas das seguintes questões: "Como os interesses e pontos de vista de um cientista podem influenciar o trabalho que ele realiza?"; "Em quais aspectos essa influência pode ser positiva?"; "Em quais aspectos essa influência pode ser negativa?". Acreditamos que as atividades acabam 
estimulando o pensamento e a participação dos alunos, o que acaba contribuindo para a criação de um ambiente que possibilita o diálogo e favorece a liberdade para os estudantes expressarem, pensarem e compartilharem sua opinião.

Atividades que propõem o trabalho em grupo também são encontradas. Essas possibilitam a união dos estudantes e debates, ensinando-os a se pronunciarem e exporem suas opiniões, bem como a respeitar o ponto de vista dos colegas. Elas promovem a cooperação, a qual para Rutz, Marinho e Silva (2018) contribui para o desenvolvimento da autonomia moral dos alunos, bem como para o desenvolvimento de uma postura mais solidária, visto que no cooperar ocorrem trocas mútuas, sustentadas pela reciprocidade.

Outro tipo de atividades, são aquelas que podem vir a ser desenvolvidas fora da sala de aula, como a atividade "observando a reprodução das pteridófitas". É uma atividade simples, que o aluno pode fazer em casa, mas com um grande propósito.

\section{RELAÇÃO CIÊNCIA, TECNOLOGIA E SOCIEDADE - CTS}

Em algumas das unidades analisadas, encontramos textos que estabelecem relações entre a Ciência e a sociedade. $\mathrm{Na}$ unidade que trata da genética, mais especificamente no tema 4 (A divisão celular), verifica-se que os autores se preocuparam com questões éticas sobre tratamentos experimentais com humanos, discorrendo sobre isso. Concebemos que é importante que o LD seja além de uma ferramenta que auxilia os alunos no seu processo educacional, um instrumento de construção do pensamento ético e crítico. Ao final dos textos das unidades, o item "Por uma nova atitude" merece destaque por ter como objetivo instigar os alunos a utilizar a genética para que se entenda problemáticas que a envolvem, tais como as doenças genéticas.

Na unidade sobre evolução, o tópico "Explorar o tema”, apresenta dois textos. No primeiro é discorrido sobre a inexistência de raças humanas sob uma perspectiva científica, baseada nos estudos genéticos e salientando que "raças humanas" não existem como entidades biológicas, e que muitas vezes esse termo é utilizado para justificar a discriminação. Já no segundo é mencionada a questão do Darwinismo social, outra questão importantíssima para discussão em grupo visto que até hoje persiste a ideia da scala naturae, onde utiliza-se de maneira equivocada os pensamentos evolucionistas para justificar que alguns grupos sociais são superiores a outros. Araújo (2012), investigando a temática "evolução" em LD, percebeu que houve uma mudança e adequação do assunto "Darwinismo social", entretanto os mecanismos que produzem as desigualdades sociais não foram explorados nos LD analisados e aprovados no PNLD para o Ensino Médio de 2012.

Na unidade adolescência e reprodução humana, no item "Saiba mais" é problematizada a questão da "revolução sexual", apresentando a importância do surgimento das pílulas anticoncepcionais para as mulheres. Nessa unidade também é discutida a técnica do "bebê de proveta" e a questão da homofobia. 0 texto que discute a homofobia apresenta perguntas como: "Por que o fazem?"; "O que temem?"; "Por que se incomodam tanto com as diferenças?". 
A incorporação de discussões atuais como estas, relacionados à Ciência, Tecnologia e Sociedade, possibilitam aos cidadãos a capacidade de debater, desmistificar e entender questões sociocientíficas, as quais não se limitam a sala de aula. Assim, sua incorporação contribui para que o aluno assuma uma postura questionadora e crítica frente às questões (PINHEIRO; MATOS; BAZZO, 2007).

\section{CONTEXTUALIZAÇÃO E INTERDISCIPLINARIDADE}

A contextualização dos conteúdos, bem como abordagens interdisciplinares foram encontradas em algumas unidades analisadas. Na unidade que tratava da evolução, logo no início, era apresentado o contexto histórico e social sobre as teorias evolutivas do século XVIII. Já na unidade sobre a genética, no tema 7 (As contribuições de Mendel para a Genética), ficou evidente uma preocupação do LD em apresentar aos alunos os assuntos da forma que foram descobertos no tempo de Mendel, recorrendo a aspectos da História da Ciência. Dessa forma, os textos apresentados nessas unidades auxiliam na contextualização do conteúdo.

Acreditamos que ao contextualizar os conteúdos e relacionar com o cotidiano do aluno, o aprendizado torna-se mais significativo. Pessano e colaboradores (2015) concebem que, na atualidade, é possível ver os distanciamentos que os processos educacionais e sociais vêm sofrendo. Os autores inferem que tal fato se deu, possivelmente, pela grande evolução social promovida pelo avanço da ciência e da tecnologia, bem como pela permanência de metodologias educacionais descontextualizadas. Ressaltam que esse distanciamento é desfavorável para os processos de aprendizagem vividos pelos sujeitos, fazendo com que a construção de conhecimentos se torne uma coisa complexa e distante da realidade vivida por eles, causando uma falta de interesse por parte dos educandos.

Dessa forma a contextualização surge como uma maneira e uma estratégia de minimizar as problemáticas vivenciadas no sistema educacional. Ruppenthal (2013) aposta que a contextualização é uma estratégia pedagógica que torna possível a mudança da realidade educacional e ainda é capaz de proporcionar a construção de um conhecimento que será significativo para o aluno.

Na unidade que trata sobre a água podemos observar uma preocupação em propor um trabalho interdisciplinar. Uma atividade proposta utiliza a obra de arte "Paraíso" de Rodolpho Tamanini Netto. Essa obra seria utilizada para demonstrar que a maior parte da água na Terra está no estado líquido. Nessa mesma unidade, utilizam-se gráficos (habilidades matemáticas) para ilustrar a importância da água e suas respectivas utilidades. Acreditamos que os benefícios de se trabalhar com saberes de outras áreas, de forma interdisciplinar, acaba proporcionando aos alunos pontos diferentes de se interligar o assunto. Dessa forma, pode ocorrer uma maior compreensão sobre o tema proposto.

A unidade que aborda a adolescência e a reprodução humana, no item "Pensar Ciência" apresenta um texto que fala sobre o número de mulheres na Ciência, no Brasil, estar se igualando ao número de homens. Nas atividades são propostas inúmeras ações interdisciplinares para os alunos: analisar a participação das mulheres na ciência no Brasil entre 1995 e 2010, bem como pesquisar o movimento feminino da década de 1960 . Sugere também para que busquem ajuda 
do professor de História para organizar um debate sobre o tema "Profissões: ainda há desigualdade entre mulheres e homens".

Ensinar de forma interdisciplinar nem sempre é uma tarefa fácil e, para que ela seja trabalhada de maneira efetiva é preciso que o educador entenda o seu real significado. Para Lago (2015), a interdisciplinaridade surge como uma necessidade de união entre diferentes disciplinas da grade curricular, as quais abrangem um mesmo assunto, tornando possível dessa maneira dar um melhor sentido para a prática educacional. Acreditamos que as ações apresentadas nas unidades analisadas convergem para esse fim e que o LD didático, trazendo essas abordagens interdisciplinares, poderá facilitar o trabalho do professor.

\section{MATERIAL COMPLEMENTAR}

Observou-se na análise que além do texto que apresenta o conteúdo conceitual há, em algumas unidades, um pequeno tópico chamado "Saiba mais" que, na unidade referente aos vertebrados, apresentou curiosidades dos animais (as mandíbulas dos tubarões e a diferença entre animais venenosos e peçonhentos). Já na unidade que tratava sobre evolução, emergem curiosidades que abordam a passagem de Charles Darwin no Brasil e a história da Terra em 24 horas.

Além disso, nas unidades são inseridas dicas de sites, como por exemplo na unidade dos vertebrados (site ra-bugio), no qual podem ser encontradas informações acerca de anfíbios brasileiros e outros animais. Na unidade que tratava da adolescência e reprodução humana, quando abordada a relação da adolescência com as mudanças físicas e hormonais que ocorrem nos corpos de meninos e meninas, é sugerido um site (www.adolescencia.org.br), o qual pode ser acessado para se obter mais informações sobre adolescência e saúde. Evidenciamos que os sites podem ampliar os conhecimentos dos alunos, aprofundando as aprendizagens obtidas em sala de aula, bem como potencializar as atividades dos professores. Dessa forma, a observação da professora B, de que gostaria que tivessem sugestões de "atividades extras" no LD, como sites, não se justifica, mostrando certo desconhecimento do material.

\section{PROBLEMAS E/OU FALTAS OBSERVADAS NAS UNIDADES}

Em relação ao conteúdo conceitual, observamos que em todas as unidades analisadas os temas foram abordados de forma muito resumida, sendo destinadas poucas páginas para os assuntos, no entanto a estruturação do conteúdo é satisfatória. Podemos exemplificar essa abordagem resumida com o que ocorre na unidade sobre os vertebrados, na qual evidenciamos um enfoque muito resumido durante a abordagem dos temas 1, 2, 3 e 4 (vertebrados, peixes, anfíbios e répteis, respectivamente). Notamos que é apresentando somente o que é "mais básico", sem aprofundar muito os assuntos, deixando de apresentar curiosidades sobre os animais ou até mesmo uma dimensão um pouco maior sobre as diferentes espécies encontradas nesses grupos. Já durante a apresentação dos temas 5 e 6 (aves e mamíferos) o conteúdo é um pouco mais detalhado e aprofundado. 
No tema 5, da unidade adolescência e reprodução humana, são abordadas as infecções sexualmente transmissíveis (ISTs) antigamente denominadas de DSTs, sendo a sigla inicial referente a doenças. Nessa parte da unidade não se evidencia um número de imagens satisfatórias para auxiliar na compreensão do tema. É apresentado apenas como se deve utilizar a camisinha masculina, negligenciando a forma de utilização da camisinha feminina.

Na unidade sobre evolução evidenciamos uma problemática corriqueira de quando se trabalha com a temática - à compreensão do tempo geológico, principalmente quando envolvem achados paleontológicos que datam milhões de anos. Percebemos uma resistência quanto à interpretação do tempo profundo, evidenciada pela ausência de uma imagem que explicasse como ocorre e como é datado os limites temporais (éon, eras e períodos geológicos). Há menção quanto a idade da vida na Terra, porém há negligência quanto a explicação do tempo geológico.

\section{CONCEPÇÕES DOS LICENCIANDOS EM CIÊNCIAS BIOLÓGICAS SOBRE O LD}

Assim como Rosa e Mohr (2016, p. 103) acreditamos que "o professor aprende a escolher o LD ao longo de sua vivência no magistério". No entanto, concebemos que atividades de análises desses materiais, nos cursos de formação de professores, são fundamentais, visto que "os professores devem ter um domínio de saberes diversos a serem mobilizados para assumir a responsabilidade ética de saber selecionar os livros didáticos" (NÚÑEZ et al, 2003, p. 3).

Emmel, Pansera-de-Araújo e Gullich (2014) evidenciam que os contextos de formação inicial de professores precisam estabelecer discussões sobre os critérios de seleção dos LD desde as licenciaturas. Corroboramos com esses autores e, além de proporcionar aos licenciandos uma atividade analítica de LD, procuramos também investigar suas concepções sobre tais recursos, antes e após analisarem criticamente o material. Tais dados apresentamos e discutimos a seguir.

As acadêmicas de Ciências Biológicas A e D mencionaram que, anteriormente a realização da análise, possuíam uma visão do LD como alunas da educação básica e "não de uma estudante de graduação em processo de formação" (Licencianda A). As percepções sobre o LD, da totalidade dos licenciandos, eram equivocadas, como podemos ver no seguinte relato: "Eu possuía uma visão totalmente equivocada sobre o LD, quando se observa o livro de maneira mais cautelosa, percebe-se que ele é uma ferramenta que pode auxiliar muito a vida de um professor" (Licenciando F).

Güllich, Pansera-de-Araújo e Emmel (2010, p. 1.910) reafirmam

o papel da formação inicial e continuada como preconizadores da discussão
acerca do tema, pontuando de modo especial que o professor precisa sempre
(re)aprender a utilizar o livro didático, de modo a exercer uma crítica
consistente e efetiva no sentido de poder delimitar o seu papel na aula de
Ciências e na sua produção de docência.

A ideia de aprender a utilizar o LD, de modo a poder delimitar o seu papel na aula de Ciências e na produção da sua docência, pode ser evidenciada nos seguintes relatos: "Após a análise comecei a ver os livros didáticos da educação básica de forma diferente. Vi que o livro traz mais que apenas os conteúdos, que 
por sinal são bem abordados, mas também apresenta questões sociais que são de extrema importância se trabalhar com os alunos" (Licencianda E); "Após a análise descobri que o LD é uma ferramenta muito boa de ensino, com fontes bem atualizadas, muitas vezes fontes de livros que utilizamos em um curso superior, com imagens muito boas e esclarecedoras. Minha concepção sobre os exercícios mudou completamente" (Licenciando F).

Pelos relatos, podemos evidenciar que após a atividade de análise do material, o recurso pode ser (re)significado pelos licenciandos. A Licencianda D mencionou que sua concepção sobre o LD foi modificada, passou a ver o recurso como uma boa ferramenta para ser utilizada nas salas de aula, mas ressalta que "ele não deve ser usado a risca pelos professores". A ressalva da aluna ilustra uma crítica consistente desenvolvida durante o processo analítico e vai de encontro ao que Núñez e colaboradores (2003, p. 3) propalam ao compreenderem que os professores devem "estar capacitados para avaliar as possibilidades e limitações dos livros recomendados pelo MEC, pois o livro deve ser um, dentre outras ferramentas, para o ensino de Ciências".

Diversos aspectos positivos nos LD foram mencionados pelos licenciandos, como: as atividades propostas (5); os textos de fácil leitura (2); a proposição de discussões para os alunos explorarem diferentes pontos de vista (1); a riqueza de imagens (1); e as atualidades (1). Podemos ver que as atividades propostas nos LD foram o grande destaque, apontadas por cinco licenciandos participantes da investigação. Vejamos alguns relatos: "ele [LD] traz o conteúdo de uma forma bem prática, mostrando mesmo o essencial e trabalhando os conteúdos com boas atividades que analisa se o aluno realmente compreendeu" (Licencianda E); "outra coisa que me chamou atenção foram os exercícios, eles são bem completos trazendo temas bem relevantes, ele [LD] os traz de uma maneira super interativa, alguns com situações-problema, fazendo com que o discente se posicione sobre o tema, outros acabam trazendo experiências que o aluno mesmo pode desenvolver" (Licenciando F).

Como falhas/problemas encontrados no material foram apontados: os textos, muito resumidos, com falta de mais conteúdo (5); alguns termos não explicados de forma clara (1); e a falta de relação com o cotidiano (1). A crítica mais recorrente se deu ao que tange aos textos das unidades serem muito resumidos, como já havia sido apontada na análise e pode ser observado nos seguintes depoimentos: "os textos muito resumidos. O livro serve como guia para o aluno e professor e não apenas como única ferramenta, entretanto senti falta de mais conteúdo no livro" (Licencianda A); "os tópicos são elaborados de uma maneira muito breve o que acaba deixando o conteúdo muito raso para os estudantes" (Licencianda B). Em relação a esses posicionamentos, compreendemos que:

O professor deve desenvolver saberes e ter competências para superar as
limitações próprias dos livros, que por seu caráter genérico, por vezes, não
podem contextualizar os saberes como não podem ter exercícios específicos
para atender às problemáticas locais. É tarefa dos professores complementar,
adaptar, dar maior sentido aos bons livros recomendados pelo MEC (NÚÑEZ
et al, 2003, p. 3).

Por fim, ao avaliarem a atividade de análise do LD, apontaram que a mesma: colaborou para a sua formação, contribuindo com o desenvolvimento de um maior senso crítico (3); proporcionou reflexão sobre como temas da Ciência são 
propostos para serem desenvolvidos na educação básica (2); possibilitou terem outra opinião sobre o uso do LD, visualizando que eles podem ser um recurso potente (2). Dessa forma, nos unimos a Rudek, Kierepka e Güllich $(2015$, p. 16), os quais sugerem a necessidade de "políticas de aperfeiçoamento dos cursos de formação de professores, que tenha como agenda permanente a discussão de temáticas como o LD". Os autores realizam essa defesa por observarem o despreparo sentido pelos professores, posteriormente, na sua atuação profissional nas escolas.

\section{CONSIDERAÇÕES FINAIS}

Como Rosa e Mohr (2016, p. 104) "não consideramos a escolha do LD como uma tarefa simples ou fácil na atividade docente". No entanto, as professoras de Ciências (as quais escolhem os LD que irão utilizar) afirmaram nunca terem recebido nenhum tipo de formação, o que as leva a escolher a partir de critérios próprios. Em relação ao uso do LD nas aulas de Ciências, esse acaba configurandose como um apoio, principalmente ao que tange aos exercícios. Tais apontamentos reforçam a importância da abordagem da discussão sobre os LD, de forma consistente, nos cursos de formação de professores, visto que:

notamos que as práticas e os conhecimentos relacionados ao LD de Ciências, seja a escolha ou o próprio uso, são experiências pouco abordadas nas formações inicial e continuada dos docentes, um problema que potencialmente repercute nas práticas dos professores com esse material ao longo de sua vida profissional (ROSA; MOHR, 2016, p. 104).

Sobre a análise das unidades, evidenciamos que os conceitos se encontram corretos, claros, adequados, assim como a linguagem empregada. A explicação da nomenclatura científica mais específica encontra-se disposta em glossários. Os textos são atualizados, a informação é precisa, mas resumida. Os conteúdos são contextualizados e as estratégias metodológicas adequadas, principalmente na proposta da forma de introdução dos assuntos aos alunos. Podemos observar uma variedade de atividades, desde práticas até o desenvolvimento de situaçõesproblema que demandam posicionamento dos alunos. Por momentos evidenciase estratégias que estimulam o desenvolvimento de ações interdisciplinares. Os recursos visuais apresentam legendas apropriadas, informando aquilo que está sendo mostrado. Também se evidencia uma relação CTS, na qual o conhecimento científico é utilizado para auxiliar a compreensão de problemas atuais e relevantes, instrumentalizando os alunos para tomada de decisões.

Nos relatos dos licenciandos observou-se que a atividade analítica modificou sua percepção sobre os LD, visto que começaram a vê-los como um recurso potente. Apontaram que a atividade colaborou para a sua formação, contribuindo com o desenvolvimento de um maior senso crítico, bem como proporcionou reflexão sobre a forma com que os temas da Ciência são propostos para serem desenvolvidos na educação básica.

Assim, por meio da triangulação de dados (concepção de professores de Ciências, análise de unidades dos LD e concepção de futuros professores de Ciências) podemos inferir que é necessário um trabalho articulado, no qual os cursos de licenciatura devem problematizar aspectos relacionados a escolhas do LD, bem como apresentar as potencialidades de sua utilização em sala de aula; 
realização de análises periódicas das coleções aprovadas pelo PNLD, para verificar como os temas estão sendo propostos, bem como a qualidade dos exemplares; e trabalhos de formação continuada com professores em exercício, para que consigam estabelecer critérios claros, os quais possibilitem a realização de uma escolha mais consciente e crítica do LD que irão utilizar.

Por fim, nesses tempos de ataque a educação em todas as suas formas, gostaríamos de encerrar o artigo retomando um pensamento mencionado por Megid Neto e Fracalanza em 2003:

A melhoria da qualidade do ensino praticado em nossas escolas públicas pressupõe, ao lado de recursos pedagógicos alternativos e variados, postos à disposição dos professores e dos alunos, também uma adequada formação inicial, aliada a uma formação contínua e permanente, bem como substantivas melhorias nas condições salariais e de trabalho dos professores da educação básica (p. 156, grifo nosso). 


\title{
The sciences textbook at stake: a triangulation between analysis of units, conception of elementary school teachers and the insight of undergraduate students of biological sciences
}

\begin{abstract}
The purpose of the work focused on carrying out a triangulation of evidences between the conceptions of elementary school Sciences teachers about the textbook (TB), analysis of the Sciences TB units used at schools in the town of São Gabriel - RS and finally analyze the conception of future Sciences and Biology teachers who will use the TB in their professional action. The research, of qualitative approach, established itself as exploratory. As research instruments, two open questionnaires were used to analyze the conceptions of the participants concerning the Sciences TB, one of them directed elementary school Sciences teachers and other answered by undergraduate students of Biological Sciences. The research participants were: six undergraduate students from the $5^{\text {th }}$ semester of the graduation course in Biological Sciences of the Federal University of the Pampa UNIPAMPA, São Gabriel Campus and three Sciences teachers from the public network of education of the town of São Gabriel - RS. The teachers mentioned they never had any training aimed at choosing the TB. The discourses show that, except at private schools, the process of choosing the TB is carried out by the teachers themselves. We highlight that the choice of the book is carried out based on some criteria. The teachers usually consider the TB as "good". Concerning the amount of books available for the number of students sometimes it is not enough precluding the possibility of having the TB taken home and therefore only being used at school. The TB in Sciences classes is used as a support, mainly for the resolution of exercises. In the analysis of the TB units, eight aspects were pointed out: presentation; language; visual resources; exercises and proposed activities; relationship Science, Technology and Society; contextualization and interdisciplinarity; complementary material; problems and/or absences/mistakes observed. According to the undergraduate students' perception about the TB it has been observed that, previous to the analytical activity, these were wrong. The main positive aspect highlighted in the TB, by the undergraduate students, were the proposed activities. As absences/mistakes/problems found in the material, most pointed out the texts, claiming that they are very short. The undergraduate students pointed out that the activity of TB analysis collaborated for their training, contributing for the development of a better critical sense; providing a reflection on how Sciences themes are proposed to be carried out in elementary education; enabled them to have another opinion about the use of the TB, noticing that it can be a powerful resource. Through the data triangulation we inferred that some coordinated work is necessary, in which the graduation courses problematize aspects concerning the choice of the TB and present the potentials of their usage for future teachers; implementation of periodic analysis of the collection approved by the PNLD in order to check how the themes are proposed as well as the quality of the materials; work on continuous training of teachers so that they can set clear criteria which enable them for a more aware and critical choice of the TB they will use.
\end{abstract}

KEYWORDS: Textbook. Science education. Teacher training. 


\section{NOTAS}

${ }^{1}$ Ciência e Educação, disponível em: http://www.scielo.br/scielo.php?script= sci_serial\&pid=1516-7313\&lng=pt\&nrm=iso. Ensaio: Pesquisa em Educação em Ciências, disponível em: http://www.scielo.br/scielo.php?script=sci_serial\&pid= 1983- $2117 \& \operatorname{lng}=$ pt\&nrm=iso.

${ }^{2}$ Para não ocasionar erro no momento da busca a palavra didático foi escrita sem acento.

3 Informações disponíveis em: BRASIL. Ministério da Educação. PNLD 2017: Ciências - Ensino Fundamental anos finais. Brasília, DF: Ministério da Educação, Secretária de Educação Básica, 2016.

\section{REFERÊNCIAS}

ARAÚJO, L. A. L. Obstáculos á compreensão do pensamento evolutivo: Análise em livros didáticos de Biologia do Ensino Médio. 2012. 77 f. Trabalho de Conclusão de Curso (Ciências Biológicas - Licenciatura) - Instituto de Biociências. Universidade Federal do Rio Grande do Sul, Porto Alegre, 2012.

ASSIS, S. S.; PIMENTA, D. N.; SCHALL, V. T. A dengue nos livros didáticos de Ciências e Biologia indicados pelo Programa Nacional do Livro Didático. Ciência \& Educação, Bauru, v. 19, n. 3, p. 633-656, 2013.

BARREIRO, M. J.; ORTENCIO FILHO, H. Análise de livros didáticos sobre o tema "morcegos". Ciência \& Educação, Bauru, v. 22, n. 3, p. 671-688, 2016.

BASSO, L. P.; TERRAZZAN, E. A. Estudo sobre o processo de escolha de livros didáticos de Ciências recomendados pelo PNLD 2013 em escolas de educação básica. Revista Cadernos de Educação, Pelotas, n. 50, p. 1-11, 2015a.

BASSO, L. P.; TERRAZZAN, E. A. Organização e realização do processo de escolha de livros didáticos em escolas de educação básica. Revista Eletrônica de Educação, São Carlos, v. 9, n. 3, p. 256-272, 2015b.

BATISTA, M. V. A.; CUNHA, M. M. S.; CANDIDO, A. L. Análise do tema virologia em livros didáticos de Biologia do Ensino Médio. Ensaio: Pesquisa em Educação em Ciências, Belo Horizonte, v. 12, n. 1, p. 145-158, 2010.

BERNARDINO, M. A. D.; RODRIGUES, M. A.; BELLINI, L. M. Análise crítica das analogias do livro didático público de Química do estado do Paraná. Ciência \& Educação, Bauru, v. 19, n. 1, p. 135-150, 2013.

BRAGA, S. A. M.; MORTIMER, E. Os gêneros de discurso do texto de biologia dos livros didáticos de ciências. Revista Brasileira de Pesquisa em Educação em Ciências, v. 3, n. 3, p. 56-74, set./dez. 2003.

CARDOSO-SILVA, C. B.; OLIVEIRA, A. C. Como os livros didáticos de Biologia abordam as diferentes formas de estimar a biodiversidade?. Ciência \& Educação, Bauru, v. 19, n. 1, p. 169-180, 2013. 
CARNEIRO, M. H. S.; SANTOS, W. L. P.; MOL, G. S. Livro didático inovador e professores: uma tensão a ser vencida. Ensaio: Pesquisa em Educação em Ciências, Belo Horizonte, v. 7, n. 2, p. 101-113, 2005.

CASSAB, M.; MARTINS, I. Significações de professores de ciências a respeito do livro didático. Ensaio: Pesquisa em Educação em Ciências, Belo Horizonte, v. 10, n. 1, p. 113136, 2008.

COUTINHO, F. A.; SOARES, A. G. Restrições cognitivas no livro didático de Biologia: um estudo a partir do tema "ciclo do nitrogênio". Ensaio: Pesquisa em Educação em Ciências, Belo Horizonte, v. 12, n. 2, p. 137-150, 2010.

DELIZOICOV; D.; ANGOTTI, J. A.; PERNAMBUCO, M. M. Ensino de Ciências: fundamentos e métodos. 4. ed. São Paulo: Cortez, 2011.

EL-HANI, C. N.; ROQUE, N.; ROCHA, P. L. B. Livros didáticos de Biologia do Ensino Médio: resultados do PNLEM/2007. Educação em revista, v.27, n.1, p. 211-240, 2011.

EMMEL, R.; PANSERA-DE-ARAÚJO, M. C.; GULLICH, R. I. C. O que dizem os professores de ciências da educação básica sobre o livro didático. Revista de Ensino de Biologia da Associação Brasileira de Ensino de Biologia (SBEnBio), v. 7, p. 6684-6693, out. 2014.

FRANCA, V. H.; MARGONARI, C.; SCHALL, V. T. Análise do conteúdo das leishmanioses em livros didáticos de Ciências e Biologia indicados pelo Programa Nacional de Livros Didáticos (2008/2009). Ciência \& Educação, Bauru, v. 17, n. 3, p. 625-644, 2011.

GREENWOOD, S. A.; FONSECA, A. B. Espaços e caminhos da educação alimentar e nutricional no livro didático. Ciência \& Educação, Bauru, v. 22, n. 1, p. 201-218, 2016.

GULLICH, R. I. C.; PANSERA-DE-ARAÚJO, M. C.; EMMEL, R. O livro didático no contexto da formação de professores de ciências/biologia e da educação científica. Revista da SBEnBio, n. 3, p. 1904-1911, out. 2010.

GULLICH, R. I. C.; SILVA, L. H. A. O enredo da experimentação no livro didático: construção de conhecimentos ou reprodução de teorias e verdades científicas?. Ensaio: Pesquisa em Educação em Ciências, Belo Horizonte, v. 15, n. 2, p. 155-167, 2013.

JOTTA, L. A. C. V. A linguagem verbal em livros didáticos de Biologia. Revista Acta Scientiae, Canoas, v. 10, n. 1, p. 119-133, jan./jun. 2008.

KRASILCHIK, M. Prática de Ensino de Biologia. 4. ed. São Paulo: Editora da Universidade de São Paulo, 2008.

LADISLAU FILHA, C. S.; RIBEIRO, G. The approach to sexuality in PNLD textbooks: a focus on STI/AIDS and condoms. Ciência \& Educação, Bauru, v. 22, n. 3, p. 773-788, 2016.

LAGO, W. L. A.; ARAÚJO, J. M.; SILVA, L. B. Interdisciplinaridade e Ensino de Ciências: perspectivas e aspirações atuais do ensino. Saberes: Revista Interdisciplinar de Filosofia e Educação, Natal, v. 1, n. 11, p. 52-63, 2015.

LAIA, S. S. O poder das imagens didáticas na construção do saber no Ensino de Ciências. 2016. 35 f. Trabalho de Conclusão de Curso (Licenciatura em Ciências Naturais) Universidade de Brasília, Planaltina, 2016. 
LEITE, A. E.; GARCIA, N. M. D. A formação inicial de professores e o livro didático de Física: passos e descompassos. Ciência \& Educação, Bauru, v. 24, n. 2, p. 411-430, 2018.

LIBÂNEO, J. C. Didática. São Paulo: Cortez, 1994.

LIMA, M. E. C. C.; AGUIAR JUNIOR, O.; DE CARO, C. M. Formação de conceitos científicos: reflexões a partir da produção de livros didáticos. Ciência \& Educação, Bauru, v. 17, n. 4, p. 855-871, 2011.

MARPICA, N. S.; LOGAREZZI, A. J. M. Um panorama das pesquisas sobre livro didático e educação ambiental. Ciência \& Educação, Bauru, v. 16, n. 1, p. 115-130, 2010.

MARTINS, E. F.; HOFFMANN, Z. Os papéis de gênero nos livros didáticos de Ciências. Ensaio: Pesquisa em Educação em Ciências, Belo Horizonte, v. 9, n. 1, p. 132-151, 2007.

MEGID NETO, J.; FRACALANZA, H. O livro didático de Ciências: problemas e soluções. Ciência \& Educação, Bauru, v. 9, n. 2, p. 147-157, 2003.

MOHR, A. Análise do conteúdo de 'saúde' em livros didáticos. Ciência \& Educação, Bauru, v.6, n.2, 2000.

MOREIRA, M. A. O questionário como um instrumento auxiliar na coleta de dados no ensino e na pesquisa em ensino. In: MASSONI, N. T.; MOREIRA, M. A. (Orgs.). Pesquisa qualitativa em Educação em Ciências: projetos, entrevistas, questionários, teoria fundamentada, redação científica. São Paulo: Editora Livraria da Física, 2016, p. 107-124.

MORI, R. C.; CURVELO, A. A. S. Química no Ensino de Ciências para as séries iniciais: uma análise de livros didáticos. Ciência \& Educação, Bauru, v. 20, n. 1, p. 243-258, 2014.

NÚÑEZ, I. B.; RAMALHO, B. L.; SILVA, I. K. P.; CAMPOS, A. P. N. A seleção dos livros didáticos: um saber necessário ao professor. O caso do ensino de Ciências. Revista Iberoamericana de Educación, v. 33, n. 1, p. 1-11, 2003.

PEDROSA, M. A. Ensino das Ciências e Trabalhos Práticos - (Re) Conceptualizar... In: VERÍSSIMO, A.; PEDROSA, A.; RIBEIRO, R. (Orgs.) Ensino Experimental das Ciências: (Re)pensar o Ensino das Ciências. Portugal: Ministério da Educação. Departamento de Ensino Secundário, 2001. p. 19-33.

PESSANO, E. F. C.; LANES, K. G.; LANES, D. V. C.; FOLMER, V.; PUNTEL, R. L. A contextualização como estratégia para a formação continuada de professores em uma unidade de atendimento socioeducativo. Revista Electrónica de Enseñanza de las Ciencias, v. 4, n. 3, p. 340-360, 2015.

PINHEIRO, N. A. M.; MATOS, E. A. S. A.; BAZZO, W. A. Refletindo acerca da ciência, tecnologia e sociedade: enfocando o ensino médio. Revista Iberoamericana de Educácion, n. 44, maio/ago. 2007.

PROCHAZKA, L. S.; FRANZOLIN, F. A genética humana nos livros didáticos brasileiros e o determinismo genético. Ciência \& Educação, Bauru, v. 24, n. 1, p. 111-124, 2018.

RIBEIRO, R. M. L.; MARTINS, I. O potencial das narrativas como recurso para o Ensino de Ciências: uma análise em livros didáticos de Física. Ciência \& Educação, Bauru, v. 13, n. 3, p. 293-309, 2007. 
RODRIGUES, M. E.; JUSTINA, L. A. D.; MEGLHIORATTI, F. A. O conteúdo de sistemática e filogenética em livros didáticos do Ensino Médio. Ensaio: Pesquisa em Educação em Ciências, Belo Horizonte, v. 13, n. 2, p. 65-84, 2011.

ROSA, M. A.; MOHR, A. Seleção e uso do livro didático: um estudo com professores de Ciências na rede de ensino municipal de Florianópolis. Ensaio: Pesquisa em Educação em Ciências, Belo Horizonte, v. 18, n. 3, p. 97-115, 2016.

RUDEK, K. M.; KIEREPKA, J. S. N.; GÜLLICH, R. I. C. O livro didático e a prática dos professores de ciências: formação e docência. Ensino de Ciências e Tecnologia em Revista, v. 5, n. 2., p. 10-18, jul./dez. 2015.

RUPPENTHAL, R. Ensino do sistema respiratório através da contextualização e atividades práticas. 2013. 104 f. Dissertação (Mestrado em Educação em Ciências: Química da Vida e Saúde) - Universidade Federal de Santa Maria, Santa Maria, 2013.

RUPPENTHAL, R.; SCHETINGER, M. R. C. O sistema respiratório nos livros didáticos de Ciências das séries iniciais: uma análise do conteúdo, das imagens e atividades. Ciência \& Educação, Bauru, v. 19, n. 3, p. 617-632, 2013.

RUTZ, K. P.; MARINHO, J. C. B.; SILVA, F. F. O trabalho pedagógico com situaçõesproblema nos anos iniciais do Ensino Fundamental em uma perspectiva construtivista. Acta Scientiae, v. 20, n. 3, p. 359-376, maio/jun. 2018.

SEVERINO, A. J. Metodologia do trabalho científico. 23. ed. São Paulo: Cortez, 2007.

SILVA, G. J.; MARTINS, C. M. C. A confiabilidade e a validação na investigação epistemológica do livro didático de química: um desenho metodológico. Ensaio: Pesquisa em Educação em Ciências, Belo Horizonte, v. 11, n. 2, p. 221-240, 2009.

SILVA, M. R.; PASSOS, M. M.; BOAS, A. V. A história da dupla hélice do DNA nos livros didáticos: suas potencialidades e uma proposta de diálogo. Ciência \& Educação, Bauru, v. 19, n. 3, p. 599-616, 2013.

SOUZA, P. H. R.; ROCHA, M. B. Análise da linguagem de textos de divulgação científica em livros didáticos: contribuições para o Ensino de Biologia. Ciência \& Educação, Bauru, v. 23, n. 2, p.321-340, 2017.

VIDAL, P. H. O.; PORTO, P. A. A História da Ciência nos livros didáticos de Química do PNLEM 2007. Ciência \& Educação, Bauru, v. 18, n. 2, p. 291-308, 2012.

VILANOVA, R. Educação em Ciências e cidadania: mudança discursiva e modos de regulação na política do Programa Nacional do Livro Didático. Ciência \& Educação, Bauru, v. 21, n. 1, p. 177-197, 2015.

XAVIER, M. C. F.; FREIRE, A. S.; MORAES, M. O. A nova (moderna) Biologia e a genética nos livros didáticos de Biologia no Ensino Médio. Ciência \& Educação, Bauru, v. 12, n. 3, p. 275-289, 2006.

ZAMBON, L. B.; TERRAZZAN, E. A. Políticas de material didático no Brasil: organização dos processos de escolha de livros didáticos em escolas públicas de educação básica. Revista Brasileira de Estudos Pedagógicos, Brasília, v. 94, n. 237, p. 585-602, ago. 2013. Médio. Ensaio: Pesquisa em Educação em Ciências, Belo Horizonte, v. 19, p. 1-22, 2017. 
Recebido: 17 abr. 2020

Aprovado: 29 mai. 2020

DOI: 10.3895/actio.v5n2.12013

Como citar:

MARINHO, J. C. B.; GONÇALVES, A. C. M.; JOSEANE SALAU FERRAZ, J. S.; GLASENAPP, G. M.;

GARCIA, K. G. S.; FELICIANI, E. C. R. O livro didático de ciências em questão: uma triangulação entre análises de unidades, concepção de professores da educação básica e visão de licenciandos em ciências biológicas. ACTIO, Curitiba, v. 5, n. 2, p. 1-24, mai./ago. 2020. Disponível em:

$<$ https://periodicos.utfpr.edu.br/actio>. Acesso em: XXX

Correspondência:

Julio Cesar Bresolin Marinho

Rua Aluízio Barros Macedo, BR 290, km 423, Bairro Piraí, São Gabriel, RS, Brasil.

Direito autoral: Este artigo está licenciado sob os termos da Licença Creative Commons-Atribuição 4.0

Internacional.

(c) (1) 